\title{
Information Logistics as a Paradigm
}

\author{
Anna E. Bobkowska \\ Faculty of Electronics, Telecommunications and Informatics, \\ Gdansk University of Technology \\ ul. Narutowicza 11/12, 80-233 Gdańsk, Poland \\ Email: annab@eti.pg.gda.pl
}

\begin{abstract}
This paper presents a paradigm-based approach to information logistics. The approach deals with extracting concepts specific to information logistics in categories typical to paradigms. The resulting description should be easily connected to complementary components which are based on other paradigms, e.g. business process management and information systems development. Empirical part aims at checking and enhancing features typical to information logistics. It is conducted with action research of applying information logistics paradigm in coordination of Erasmus+ program.
\end{abstract}

\section{INTRODUCTION}

$\mathrm{I}$ NFORMATION logistics has been a topic of research for about three decades with more than hundred contributions nowadays [1], [2]. It has several definitions with focus on a variety of issues in different contexts of use. A common motive for information logistics is transfer of the right information to the right place in the right time. The main active research directions are user-demand information supply [3], [4], efficiency of information flow [5], [6], cross-functional supply of analytical information [7], [8] and process improvement via information flow [9]. About two dozens of organizations offer their information logistics products for real-life solutions. One can observe that information logistics in real-life applications cannot be separated neither from defining chains of information processing and delivery nor from automation of information processing by software systems. Many information logistics products are based on Information and Communication Technologies (ICT) and support Business Process Management (BPM). Therefore, there is a need to explore relationship between information logistics, business process management and software engineering.

The goal of this paper is to analyze information logistics from the perspective of paradigm theory. It deals with extraction of concepts specific to information logistics and connection of resulting descriptions to components of solution which use other paradigms. Fig. 1 presents a schema of paradigm-based approach to integrating information logistics to other components using meta-modeling technology.

This approach is motivated by the following reasons. First, information logistics, business process management and software systems are complementary components of real-life solutions. They focus on different aspects and can be captured more precisely in terms of paradigms. The notion of paradigm is related to extraction of basic concepts specific to a given area and it allows to avoid uncontrolled overlapping with basic concepts from other paradigms. Sec- ond, the use of paradigm-based approach makes a difference in viewing information logistics. It makes a shift from entire information logistics solution (which informally defines enterprise processes and uses information systems) to a kind of specific component which can be connected to components which are based on other paradigms. The benefit of such approach is in solving each class of problems in the most effective technology and then connecting them in complete solution of real-life problems. Third, information logistics paradigm constitutes foundations for formalization of the paradigm with the meta-modeling technology provided by $\mathrm{Ob}-$ ject Management Group (OMG), especially in terms of UML profiles. OMG Unified Modeling Language (UML) [10] defines object-oriented software development perspective and OMG Business Process Model and Notation (BPMN) [11] defines business process management perspective. OMG offers UML profiles as extension mechanism and defines a profile diagram for the purpose of defining new UML profiles [12]. With use of this technology, formalisms which define all these complementary paradigms are expressed with the same meta-meta-models, which provides a strong common ground for integration and interoperability. This research shows that information technologies can offer to logistics not only methods and environments for computations or methods of information systems engineering, but also benefits from applying advanced meta-modeling technologies.

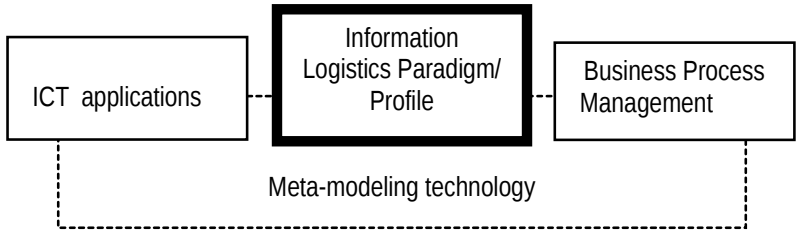

Fig. 1 A schema of integration of information logistics profile with other components of solution with use of meta-modeling technology

This paper is structured as follows. Section 2 presents and exploits paradigm-based approach. It explains the role of paradigms in computer science adhering to Kuhn's paradigms in philosophy of science, attempts to apply paradigms in computer science as well as multi-paradigm modeling approach and defines categories typical to paradigm description (paradigm template). Then, it describes analysis of information logistics definitions in literature made in order to capture core concepts and issues in information logistics. Section 3 contains description of action research in which features specific to information logistics are checked and en- 
hanced when solving real-life problems in the area of coordination of Erasmus + program. Section 4 makes an attempt to describe information logistics paradigm on the basis of both analytical and empirical parts. Section 5 presents conclusions and plans for further work.

\section{INFORMATION LOGISTICS AS A PARADIGM}

\section{A. Fundamentals of Paradigms}

The popularity of the term paradigm, which has its roots in ancient Greak $\pi \alpha \rho \alpha \delta \varepsilon i \gamma \mu \alpha$ meaning pattern, examplar, example, has been a contribution of a philosopher of science Thomas Kuhn, who explained incommensurability of theories in science by adhering to their diversified fundamentals. A paradigm in mature science stands for a set of fixed key theories, scientific language, values and metaphysical assumptions as well as procedures and instrumentation needed to solve practical problems [13].

The notion of paradigm corresponding to software has first appeared as paradigms of programming [14] with decreasing scope of paradigm as a side effect of moving the term of paradigm from science to technology. Then, it was elaborated in context of several reuse approaches to software development including design patterns, components, software architectures and frameworks [15]. Another use of this term can be found in multi-paradigm modeling approach [16], [17] which aims at dealing with heterogeneous solutions. The need for effective solutions has made a difference in viewing paradigm. It has replaced initial incommensurability of theories in science by the request for pragmatic integration of technologies which are based on different paradigms.

A paradigm-based approach is based on the following assumptions. Different classes of problems have effective solutions in technologies which use different paradigms. In order to develop software applications which deliver business value to customers there is a need to integrate technologies which are based on different paradigms.

When comparing paradigm-based approach with typical systems development the following differences can be identified. Typical development may be easier in simple cases whilst paradigm-based approach may require extra effort on interface definitions and collaboration between components based on different paradigms. On the other hand, solutions made with paradigm-based approach are easier to maintain especially when integral components need to be updated. It can deal more effectively with heterogeneous cases. Additionally, it is easy to connect to newly added components. It can provide more precision with traceability to sources. The challenge is in assessing global features of solutions. As this is a quite new approach, few experience reports from its applications are available.

\section{B. Questions and Methods}

In order to capture information logistics as a paradigm there is a need to define knowledge gathered in this field of study in categories specific to paradigms. Thus, the following questions can be posed for information logistics: What are its values and (metaphysical) assumptions? What are its scientific language and key theories? What is the class of problems that can be solved effectively in this paradigm?
What are instrumentation and procedures, i.e. methods and technologies, needed to solve these problems? How to integrate it with technologies which use other paradigms in context of paradigm-based approach?

We assume that information logistics paradigm should be based on its strong connotations to logistics. The intuitive understanding of information logistics is a kind of logistics which is related to information instead of material goods and services.

In order to capture the essentials of information logistics we have searched for common themes in information logistics definitions and notions provided by both researchers and practitioners collected in literature overview [1], [2]. Number of appearance of a given common theme against total number of definitions analyzed is presented in brackets.

Then, we have conducted a cross-analysis of these common themes with themes in logistics management definition provided by the Council of Supply Chain Management Professionals in order to check whether the common themes are strongly related to logistics and thus they have appropriate connotations to logistics.

A related field of study is information management. Therefore, we have compared our approach with the approach presented in Information Management Body of Knowledge.

\section{Common Themes of Information Logistics}

Common themes of information logistics include:

- right information (20/33) with more precise specification of what is right information in terms of content or format $(8 / 33)$, way or channel $(3 / 33)$, size $(1 / 33)$, quality $(6 / 33)$ and requirements, needs or demands $(6 / 33)$;

- right time (20/33) with adhering to "just in time" philosophy $(3 / 33)$ or efficiency $(5 / 33)$;

- right place or location (16/33) with additional distinction to recipient or person (7/33) or target group (3/33);

- information flow $(9 / 33)$ or information value chains $(5 / 33)$;

- $\quad$ right cost or optimization of costs $(6 / 33)$;

- two cases: information distribution and information about logistics of goods and services;

- $\quad$ operational activities (8/33) of gathering (2/33), selecting (2/33), production, receiving, processing, organization, optimization, storage (3/33) and distribution (6/33); focusing on dissemination rather than production and classification;

- managerial activities of planning (2/33), control and implementation (1/33);

- infrastructure in terms of network of suppliers-requestors $(1 / 33)$ or information logistics infrastructure with information systems support (13/33);

- relationship to other fields (2/33), such as information management, knowledge management, communication management and business networks.

The above classification of themes may be biased in several ways. Definitions and notions may not cover full range of issues addressed by research results or products. The analysis was made on the basis of selection of issues in cited literature overview. There are probably implicit relationships between research results, research bodies statement of notion 
and information logistics product providers. Therefore, the generalization of the common themes coverage to quantitative coverage of themes in the area of information logistics may be unjustified. However, they reflect quite well essentials and issues in this area.

\section{Cross-Analysis with Logistics Management}

Council of Supply Chain Management Professionals (CSCMP) provides the following definition of logistics management [18]: "Logistics management is that part of supply chain management that plans, implements, and controls the efficient, effective forward and reverse flow and storage of goods, services, and related information between the point of origin and the point of consumption in order to meet customers' requirements. Logistics management activities typically include inbound and outbound transportation management, fleet management, warehousing, materials handling, order fulfillment, logistics network design, inventory management, supply/demand planning, and management of third party logistics services providers. To varying degrees, the logistics function also includes sourcing and procurement, production planning and scheduling, packaging and assembly, and customer service. It is involved in all levels of planning and execution-strategic, operational, and tactical. Logistics management is an integrating function which coordinates and optimizes all logistics activities, as well as integrates logistics activities with other functions, including marketing, sales, manufacturing, finance, and information technology."

Table I presents a comparison of the common themes in information logistics with related logistics management themes. It shows that in almost all categories some equivalents can be found although they have different focus. The common themes of information logistics focus on provision and distribution of right information at the right time to the right place. Explosive speed of information available via global ICT applications, the need for gathering crucial business information and chaos of information in organizations are the main motivations for such statements of expected effects. Less attention is paid to the core term of logistics which is supply chain (similar to information flow and information value chain). In fact, logistics definition contains a suggestion that right information, time and place should be placed in a broader perspective of flows which contribute to a more complex enterprise.

For many logistics operations one can find equivalents in information logistics although they have their specifics or smaller importance. Equivalents of transportation are distribution, dissemination, gathering and receiving depending on context. Warehousing corresponds to storage. Logistics network design and fleet management are related to infrastructure management. Supply/demand planning finds its implementation in information flow design. Similar to auxiliary production planning and scheduling may be production, processing and optimization. Thus, on operational level, the analogy is quite strong. Logistics management can broader horizons of information logistics management. Although managerial activities of planning, control, implementation as well as relationships to other fields have been identified in scope of common themes for information logistics, logistics management is involved in all levels of planning and execu-
TABLE I.

COMPARISON OF COMMON THEMES IN INFORMATION LOGISTICS WITH RELATED LOGISTICS MANAGEMENT THEMES

\begin{tabular}{|c|c|}
\hline $\begin{array}{l}\text { COMMON THEMES IN } \\
\text { INFORMATION LOGISTICS }\end{array}$ & $\begin{array}{l}\text { LOGISTICS MANAGEMENT } \\
\text { THEMES }\end{array}$ \\
\hline $\begin{array}{l}\text { information flow or information } \\
\text { value chains }\end{array}$ & $\begin{array}{l}\text { a part of supply chain manage- } \\
\text { ment }\end{array}$ \\
\hline $\begin{array}{l}\text { managerial activities of planning, } \\
\text { control and implementation }\end{array}$ & $\begin{array}{l}\text { actions: plan, implementation and } \\
\text { control }\end{array}$ \\
\hline $\begin{array}{l}\text { two cases: information distribu- } \\
\text { tion and information about logis- } \\
\text { tics of goods and services }\end{array}$ & $\begin{array}{l}\text { efficient, effective forward and } \\
\text { reverse flow and storage of goods, } \\
\text { services, and related information }\end{array}$ \\
\hline $\begin{array}{l}\text { right place (location) with addi- } \\
\text { tional distinction to person or tar- } \\
\text { get group }\end{array}$ & $\begin{array}{l}\text { between the point of origin and } \\
\text { the point of consumption }\end{array}$ \\
\hline $\begin{array}{l}\text { right information in terms of con- } \\
\text { tent or format, way or channel, } \\
\text { size, quality or requirements, } \\
\text { needs or demands }\end{array}$ & $\begin{array}{l}\text { in order to meet customers' re- } \\
\text { quirements }\end{array}$ \\
\hline \multirow[t]{2}{*}{$\begin{array}{l}\text { operational activities of gathering, } \\
\text { selecting, production, receiving, } \\
\text { processing, organization, opti- } \\
\text { mization, storage and distribution; } \\
\text { focusing on dissemination rather } \\
\text { than production and classifica- } \\
\text { tion; } \\
\text { infrastructure in terms of network } \\
\text { of suppliers-requestors or infor- } \\
\text { mation logistics infrastructure } \\
\text { with information systems support }\end{array}$} & $\begin{array}{l}\text { typical activities: inbound and } \\
\text { outbound transportation, fleet } \\
\text { management, warehousing, mate- } \\
\text { rials handling, order fulfillment, } \\
\text { logistics network design, inven- } \\
\text { tory management, supply/demand } \\
\text { planning, and management of } \\
\text { third party logistics services } \\
\text { providers }\end{array}$ \\
\hline & $\begin{array}{l}\text { all levels of planning and execu- } \\
\text { tion: strategic, operational, and } \\
\text { tactical }\end{array}$ \\
\hline $\begin{array}{l}\text { right cost or optimization of costs; } \\
\text { right time with adhering to "just } \\
\text { in time" philosophy or efficiency }\end{array}$ & $\begin{array}{l}\text { integrating function which coordi- } \\
\text { nates and optimizes all logistics } \\
\text { activities }\end{array}$ \\
\hline $\begin{array}{l}\text { relationship to other fields, such } \\
\text { as information management, } \\
\text { knowledge management, commu- } \\
\text { nication management and busi- } \\
\text { ness networks. }\end{array}$ & $\begin{array}{l}\text { integrates logistics activities with } \\
\text { other functions, including market- } \\
\text { ing, sales, manufacturing, finance, } \\
\text { and information technology. }\end{array}$ \\
\hline
\end{tabular}

tion, i.e. strategic, operational, and tactical and it covers integrative activities of coordination and optimization of all logistics activities as well as activities in related fields.

\section{E. Comparison to Information Management}

One could ask questions: What is the relationship between information logistics and information management? Don't they deal with the same problems? (It seems similar to questions: What is the relationship between logistics and resource management? Don't they deal with the same problems?) In our opinion, information logistics and information management represent different traditions of research which address overlapping problems and deliver overlapping results. Additionally, both terms are broad and abstract, which makes difficulty in comparisons. One can expect that internal inconsistencies in both fields are encountered. In this situation, we compare only proposed paradigm-based approach to information logistics with a concrete representation of information management in Information Management Body of Knowledge (IMBOK) [19].

IMBOK addresses problem of "huge complexities in the territory where information technology, business and society meet". It divides information management to six knowledge areas: information technology, information systems, business processes, business information, business benefits and 
business strategy. It describes four types of information management processes:

- projects related to information systems development with use of information technology,

- business change which makes changes in business process and business information areas with information systems,

- business operations which lead to accomplish business benefits,

- performance management where business strategy and business benefits meet.

Table II presents a comparison of paradigm-based approach to information logistics with IMBOK. Although the terms information logistics and information management seem to have a similar meaning, both have a broad scope and both include several approaches. The comparison which was made, shows that the differences might be on the level of fundamental assumptions, such as goals, focus, scope and values. (Information logistics solutions which use a more holistic approach could have more similarities to information management.) In fact, this is an example of incommensurability of theories in science, as Thomas Kuhn would call it. To continue his thought: established scientific paradigms, committed groups of researchers and consistent research results are the signs of mature science.

One of the common themes includes information management on the list of fields to which information logistics has relationships. This relationship may take form of appropriate application of relevant theories and techniques in concrete cases of information logistics solutions.

\section{TABLE II.}

COMPARISON OF PARADIGM-BASED APPROACH TO INFORMATION LOGISTICS WITH IMBOK

\begin{tabular}{|c|c|}
\hline $\begin{array}{l}\text { PARADIGM-BASED APPROACH TO } \\
\text { INFORMATION LOGISTICS }\end{array}$ & IMBOK \\
\hline $\begin{array}{l}\text { Information logistics profile as a } \\
\text { component to be connected with } \\
\text { others }\end{array}$ & $\begin{array}{l}\text { Framework to cover complexities } \\
\text { on the edge of IT, business and so- } \\
\text { ciety }\end{array}$ \\
\hline $\begin{array}{l}\text { Focus on extracting and formaliz- } \\
\text { ing specific features of information } \\
\text { logistics }\end{array}$ & $\begin{array}{l}\text { Focus on a big picture, i.e. "every- } \\
\text { thing that has anything to do with } \\
\text { information in business" }\end{array}$ \\
\hline $\begin{array}{l}\text { Starts with transfers of the right in- } \\
\text { formation at the right time to the } \\
\text { right place with interface to busi- } \\
\text { ness process management (includ- } \\
\text { ing IMBOK business processes, in- } \\
\text { formation, benefits and strategy) } \\
\text { and interface to ICT application } \\
\text { (including IMBOK information } \\
\text { technology and information sys- } \\
\text { tems) }\end{array}$ & $\begin{array}{l}\text { Covers: } \\
\text { - information technology, } \\
\text { - information systems, } \\
\text { - business processes, } \\
\text { - business information, } \\
\text { - business benefits, } \\
\text { - business strategy }\end{array}$ \\
\hline $\begin{array}{l}\text { Value of external consistency with } \\
\text { standards and easy update when } \\
\text { they evolve }\end{array}$ & Value of addressing entire field \\
\hline
\end{tabular}

\section{ACTION RESEARCH BASED ON COORDINATION IN ERASMUS+ PROGRAM}

\section{A. Motivation}

Information Logistics paradigm seems to be helpful in coordination of Erasmus + program [20]. There is a need to define rules and procedures, but business process perspective is not sufficient for capturing all aspects of the reality. Many parties are involved with their specific information needs. Changes are made outside of control of coordinators. There are several regulations of different kinds which need to be satisfied. Long documents which sometimes require interpretations and informal rules applied in order to unify action in similar exceptional cases cause difficulty to clearly understand the rules for those who just occasionally are involved in the program. The perspective which suggests to pose questions: What is the right information? What is the right time? What is the right channel to get to a given target? is helpful in systematic elaboration of the right solution in this complicated situation.

\section{B. Action Research Description}

The goal of the action research is to check common themes of information logistics in a practical case and to enhance them by extracting new features specific to information logistics. The objective of the actions is to improve information logistics processes during coordination of Erasmus+ program in terms of analysis and explicit definition of the needs for information transfers, their content, channels and feedback. It should lead to a higher level of satisfaction of the parties involved in the processes. As the author fulfills duties of Faculty Erasmus + coordinator, practical benefits resulting from process improvement this area are expected.

It is expected that the common themes of information logistics drive attention to several useful features which can be analyzed for process improvement. After validation and enhancements, they should be included in paradigm description. Managerial tasks should help in building framework for management. Operational activities are expected to help in extracting stereotypes of activities. Important issues of analysis are how to develop infrastructure and how to optimize effort related to its construction.

In the next section, an attempt to capture complexity of actions with traditional techniques and some limitations of their application are presented. In the further part, information logistics issues are analyzed. The following issues are discussed in details:

- goals of information transfer,

- management of group dynamics,

- flexibility of processes depending on diversity and changes in areas controlled by external participants,

- promotion via different channels,

- the right information at the right time and in the right place.

The descriptions are made according to the following template:

- description of the issue under consideration,

- comparison to business process management (BPM) perspective, especially to elements of BPMN,

- $\quad$ examples from the area of actions.

The comparison to BPM is made because business process and chain of information flow are similar concepts. Furthermore, analysis of relationships between information transfer and business process management is important from the perspective of making relationships between complementary paradigms which must work together in order to deliver solution. 


\section{An Attempt to Capture Complexity of Actions}

In order to deal with complexity of actions related to coordination and management of Erasmus + program, several techniques available for project managers or business analysts can be applied with quite satisfactory results, e.g. stakeholder analysis, document analysis, organization modeling, process modeling, checklists, regulations and checking their compliance with framework regulations, metrics and key performance indicators. However, due to large diversity of cases, large dynamics and coordinative specifics, the application of these methods reveal some limitations. They are useful at higher level of abstraction, but it seems to be impossible to cover and trace all details of changes in a reasonable time. The resulting need for flexibility reduces the applicability of methods which tend to unification and formalization.

Fig. 2 presents stakeholders who require coordination during the Erasmus + exchange actions. Erasmus + agencies at European and national level as well as university authorities provide a variety of rules and regulations and then require documents and several kinds of reports. They influence mainly strategy and tactical levels. Other stakeholders are interact at operational level. The diversity of rules at partner university (including national regulations, university processes and on-line systems) has impact on all processes of exchange. It is reasonable that the work on information logistics is based on the results of stakeholder analysis.

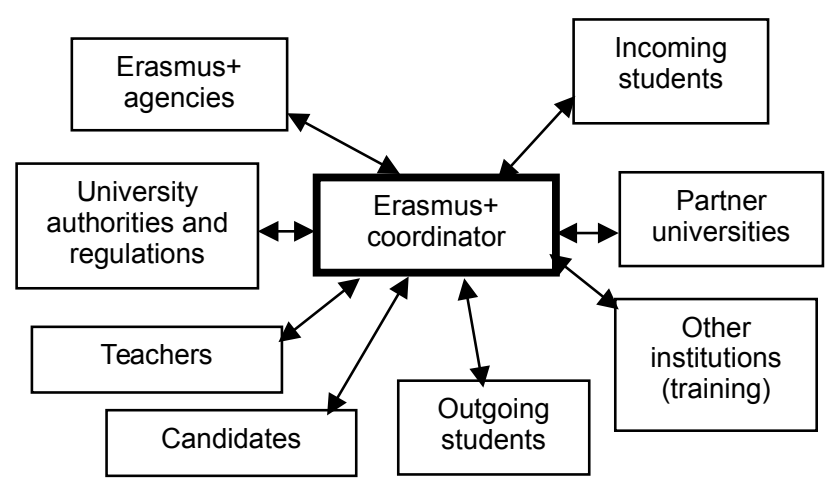

Fig. 2 Stakeholders who require coordination during the Erasmus + exchange actions

High-level business process descriptions are useful for organizing and ordering the actions. However, due to coordinative specifics of these actions, low level business process descriptions does not reduce much complexity, i.e. it does not reduce neither the number of participants of a specific interaction nor helps in defining a single sequential course of actions. Furthermore, it seems that business process management paradigm has been invented to solve a slightly different problems than these appearing in coordinative actions.

\section{Goals of Information Transfer}

Description: Goals of information transfers need to be defined because they are not default and they can be related to several actions with different effects. The goals organize related information transfers and they can be divided in subgoals.
Comparison to BPM: A given business event usually starts business process which is strictly defined and formats of documents are fixed. Business goals and objectives are defined at higher level of business policy and strategy or they result from business process decomposition. Information transfers may be more flexible and thus more creativity can be involved in action. The goal acts as a frame of reference.

Example: Let's assume that the goal is to inform students about possibility to take part in Erasmus+ program, about the rules and recruitment procedure. It can be implemented via several actions which can be stated as subgoals such as:

- provide short information via posters,

- organize a meeting,

- provide detailed information on the website,

- $\quad$ send e-mails to the students who expressed their interest,

- $\quad$ send short message via existing information systems. Each of the sub-goals can be decomposed to several actions and information transfers which need proper management.

\section{E. Management of Group Dynamics}

Description: Information logistics defines target in terms of both individuals and groups. Formation of groups and subgroups allows for increasing efficiency comparing to individual treatments. It is worth to mention that these groups and sub-groups might be very dynamic. Therefore, group management and customization of messages is necessary. The benefits are visible when rapid reaction on changes is possible and when right information goes to the right target group. This action can be classified as an infrastructure management action.

Comparison to BPM: Participants and their responsibilities in business process can be specified in terms of swimlanes. BPMN allows to specification of multi-instance pools on conversation diagram, multi-instance participant on choreography diagram and multi-instance task on collaboration diagrams. However, no support for modeling dynamic change of participant's role is provided, i.e. phenomena that the same physical participant becomes a participant on a different pool.

Example: Let's consider a group of students interested in Erasmus + exchange. Some of them can belong to a subgroup of students interested in bilateral agreements related to mobility. Another sub-group may be interested in offers of training. New students can be added to these groups as well as some students might want to withdraw. Another group of students are candidates for exchange, who can be divided with recruitment decisions for these nominated and those who are not. The sub-group of nominated students can be further divided for a sub-group of these who fulfill all requirements of application procedure and get accepted on one hand and a sub-group of those who do not achieve it on the other hand. All these changes happen dynamically in process and they cannot be predicted from the start. 


\section{F. Flexibility of Processes Depending on Diversity and} Changes in Areas Controlled by External Participants

Description: The difficulty in defining fixed processes with strictly defined information transfers might be caused by dependence on external participants who act according to the diversity of processes and they can make changes without notification. Thus, goals can be achieved via flexibility of action together with active processes of information acquisition.

Comparison to BPM: Business processes are usually fixed with limited number of routes connected by appropriate gateways. It is assumed that external data are inserted by participants within the defined processes. The difference in information logistics approach is in the need to customize the process and the content of information transfers to the requirements and specifics of external participants.

Example: The processes of sending nominations for exchange students and rules of application procedures are good examples of the diversity. Most universities accept nominations of exchange students by e-mail, but there are some exceptions, e.g. nominations via their on-line system or application by students themselves first with confirmation by coordinators later on. The number of combinations of online systems and kinds of required documents in paper in a variety of formats and ways of delivery is really large. Furthermore, these actions are spread over time adhering to different schedules and they are performed for a large numbers of students. These circumstances cause that they are really difficult to manage without systematic information logistics methods.

\section{G. Promotion via Different Channels}

Description: Information logistics may require promotion management in order to reach target group. It needs to be done via different channels and insights from marketing studies are useful in order to make it effectively.

Comparison to BPM: This issue is specific to marketing and it is not present in BPM.

Example: Typical promotion is made in order to inform students about Erasmus+ program. In section III.D several sub-goals related to different channels were described. It is worth to mention that is should be a consistent campaign with use of creative methods as well as traditional ones.

\section{H. The Right Information at the Right Time and in the Right Place}

Description: This statement could be a motto for information logistics as it covers the most popular common themes. It is good to understand that these are main dimensions of each information transfer and they should be assured all together.

Comparison to BPM: BPMN contains element called data object which represents information flowing through the business process. Timing and participants are described on collaboration diagram in context of the business process. The difference is in focus indicated by the word right, i.e. in information logistics one should analyze the needs for the right information at the right time and in the right place from the perspective of participant rather than optimization of request processing.
Example: In context of large amounts of rules and regulations the idea to provide the right information at the right time really promises to save participants time, increase confidence of action, and thus increase their satisfaction. Apart from general orientation, exchange students have different needs for detailed information on several stages of preparation to exchange. Before recruitment they need information about the rules and deadlines of recruitment. Then, they need details of other stages: application, actions after acceptance, actions during their stay and actions at departure. It is easier to prepare just one presentation for all, but the perspective of information logistics suggests that there should be separate information packages adhering to the paradigm of the right information at the right time to the right participants.

\section{Discussion}

This action research was conceptually inspirational. It allowed to see the reality of Erasmus + program coordination in the new perspective of information logistics. The connotations to logistics, transfers of right packages of information to right target just in time and the notion of infrastructure activate imagination to work on innovations in the coordination processes. Analysis according to the common themes in information logistics has driven attention to the aspects which were not analyzed in detail before and allowed to see them more clearly. The dimensions of the right information transfers, details of group dynamics and more clear understanding of changes controlled by external participants with related need for flexibility of processes should be taken into consideration when making changes in the process together with traditional techniques of business analysis and project management. To conclude, this action research (from the perspective of process improvement) has provided inspiration, useful terminology and solid bases for making decisions about improvements.

From the perspective of research on information logistics, it has appeared that the common themes are at very different level of abstraction. Some of them are very concrete and they can be transformed to an attribute of information transfer, e.g. content of information transfer. On the contrary others are extremely general without indication on operational action, e.g. relationship to other fields such as information management, knowledge management, communication management and business networks. These common themes which are concrete have led to more detailed results in analysis. Those more general require an extra effort to make them work. Regarding the enhancement to common themes, the examples of issues are hierarchy of goals of information transfers, management of group dynamics, and flexibility of processes depending on diversity. The question arise whether they are typical to several information logistics problems or they are specific just to the domain of this action research.

It seems that the common theme of information flow or information value chain is a good proposition for a common ground between information logistics and business process management. Actions related to sequences of information flows can be described by business processes. Information transfer details, such as channel, demands, content, time, size and quality constraints, can be 
provided by information logistics perspective. This action research has confirmed that business process management perspective is not sufficient to cover all aspects specific to information logistics. The issue of the right information at the right time and in the right place (III.H) shows that these approaches can be complementary. The goals of information transfers (III.D) sometimes correspond to business process but sometimes to a more general concepts in business strategy. Flexibility of processes and their changes (III.F) might be represented in their description, however this activity is profitable only when the cost of process update is lower than the cost of acquiring updated information when it is needed. The changes in assignments of individuals to group and dynamic change of roles (III.E) seem to be in opposition of business process fundamentals of having clearly defined participants of interaction. Promotion via different channels (III.G) is an example of issue which is outside of area of business process management. Therefore, this action research has revealed several shades of relationship between information logistics and business process management.

\section{TOWARDS INFORMATION LOGISTICS PARADIGM}

The following attempt to define information logistics paradigm is based on both analytical results and action research insights with the categories of paradigms identified on the bases of paradigms in philosophy of science adjusted to technological context. Fig. 3 shows the contribution of the parts of presented research for the components of information logistics paradigm description.

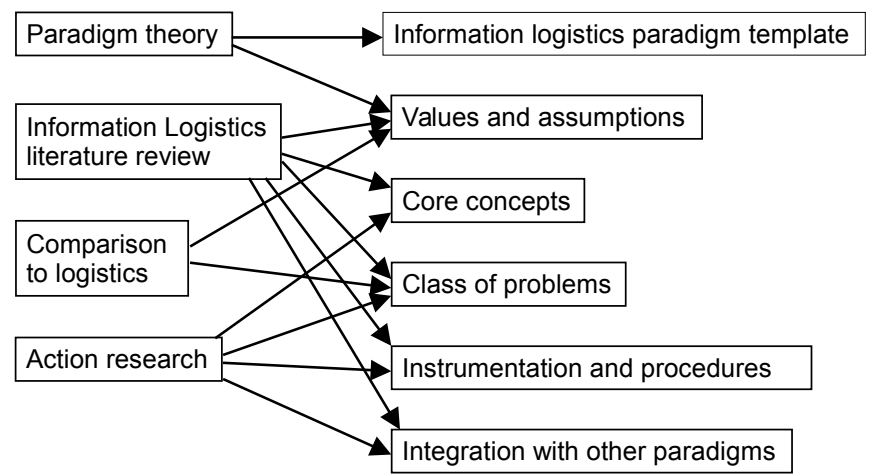

Fig. 3 Relationship between the parts of research and the components of paradigm template

\section{A. Values and Assumptions}

Values come from two kinds of sources. The first one is paradigm-based approach with its tendency to define typical solutions in terms of paradigms and allow for integration of different paradigms for real-life solutions. The second source is the area of information logistics which has identified several concepts and issues related to information logistics. In the diversity of the field, the value of strong connotations to logistics acts a point of reference when making decisions.

\section{B. Core Concepts}

Mature paradigms have their scientific language and key theories. The first step to define them for Information Logistics is a common language expressed as core concepts pre- sented in Fig. 4. It details concepts related to information transfer and envisages the need for further elaboration with two packages of Activities and Infrastructure.

\section{Class of Problems}

Information logistics can effectively solve problems which appear as information chaos in organizations or during collaboration with other organizations. They usually happen in context of large amounts of information, large numbers of stakeholders with different information needs, changes of information outside of control of those who manage it, needs to access to crucial business information at the right time, needs for flexible and informed customizations to external parties as well as dynamic emergence of new information suppliers, requestors or channels.

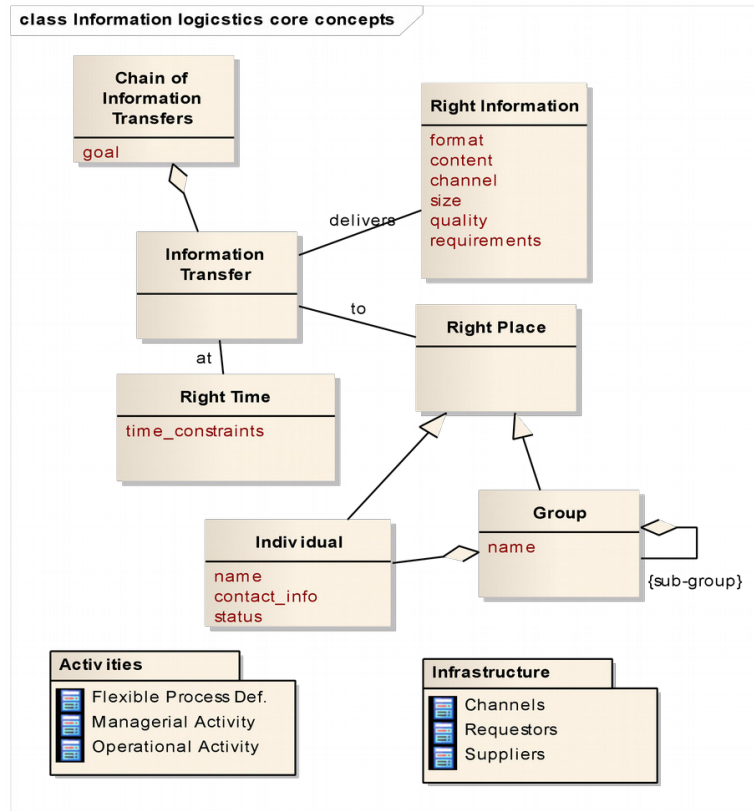

Fig. 4 Core concepts of Information Logistics

\section{Instrumentation and Procedures}

Methods and technologies constitute technical equivalents for instrumentation and procedures in scientific context. They include ICT applications as well as techniques for visualization, case management, information transfer optimization, etc. In this approach a few kinds of methods can be distinguished. These can be methods specific to information logistics and methods for integration with other fields of study. Another classification can distinguish between methods for defining, elaborating and improving solution and methods for working with solution.

\section{E. Integration with Other Paradigms}

The main connection point needs to be defined to business process management. The chains of information transfers are complementary to operational activities related with information acquisition and processing in context of circumstances which can be defined as stages of processing. The second connection point should direct to effective ICT systems which support users in performing their tasks. Other connection points can be made to results from related fields 
of study, such as marketing studies, information management, knowledge management, communication management and business networks. They address connection points related to solution. Other connection points can be made to techniques for elaborating solution, e.g. in the areas of business analysis and project management.

\section{CONCLUSIONS AND FURTHER WORK}

The paradigm-based approach is based on assumption that different classes of problems have effective partial solutions in technologies which use different paradigms and there is a need to integrate technologies which are based on different paradigms when developing real-life solutions. Information logistics can be viewed as a paradigm. This paper has addressed the first task on the way towards information logistics paradigm, which was the extraction of concepts specific to information logistics and the attempt of their description in categories specific to paradigms.

A frame of reference for categories specific to paradigms was elaborated on the basis of paradigms in philosophy of science and contemporary uses of the term of paradigm in computer science. When taking into account a large number of diversified definitions of information logistics in literature, the decision was made to build information logistics paradigm with the value of strong connotations to logistics, i.e. information logistics is a kind of logistics which is related to information instead of material goods and services.

Core concepts were extracted with analysis of common themes of information logistics definitions and notions provided by both researchers and practitioners. The essentials of information logistics appeared to be transfer of the right information at the right time to the right place. Common themes allowed to identify several issues, such as chains of information flow, cost optimization, distinction between two cases: information distribution and information about logistics of goods and services, types of operational activities with focus on dissemination rather than production and classification; managerial activities and infrastructure management, and relationships to other fields of study such as information management, knowledge management, communication management and business networks.

In order to keep compliance to the value of strong connotation to logistics, the cross-analysis was made in which the common themes were compared with themes of logistics management definition provided by the Council of Supply Chain Management Professionals. It has shown that in almost all categories some equivalents can be found although they have different motivation and focus. A brief comparison to Information Management Body of Knowledge was also made because information management and information logistics are related areas. The comparison has shown that, despite of similarities, diversity in approaches still exists.

The empirical part was made as action research in the area of coordination of Erasmus + program. With the experience of facing real-life problems, the following issues have been discussed: need to set up a hierarchy of goals of information transfers, management of group dynamics, flexibility of processes depending on diversity and changes in areas controlled by external participants, promotion via different channels, and problems with the right information at the right time and in the right place. Each issue has been illustrated with the examples and comparison to business process management perspective has been discussed. A summary of issues on the edge of information logistics and business process management shows diversity of cases starting from clear complementary relationship, via issues which require consideration according to criteria from yet another perspective, to the situation where business process cannot help because they do not deal with these issues.

Both analytical research results and action research have contributed to an attempt to formulate information logistics paradigm. Within further work it is planned to supplement the model with more concepts specific to information logistics, formulate a proposal of UML profile for Information Logistics and provide connections to related technologies which are based on other paradigms. The concepts specific to information logistics can be gathered with more detailed review of related work in information logistics area. A proposal of UML profile for information logistics can be done with application of meta-modeling technology delivered by OMG. The most challenging task is providing connection to technologies which are based on other paradigms since there is no certainty whether it can lead to general results or these relationships are specific to a case at hand. Additionally, the research could benefit from more empirical research results conducted also in different domains.

\section{REFERENCES}

[1] D. Haftor, M. Kajtazi, A. Mirijamdotter, "A Review of Information Logistics Research Publications" in Lecture Notes in Business Information Processing LNBIP 97, 2011, DOI: $10.1007 / 978-3-642-25370-6 \_24$.

[2] D. Haftor, M. Kajtazi, "What is information logistics? An explorative study of the Research Frontiers of Information Logistics", 2009, Inu.diva-portal.org (access 7.05.2015)

[3] M. Apelkrans, and A. Håkansson, "Enterprise Systems Configuration as an Information Logistics Process - A Study" in Proceedings of the 9th International Conference on Enterprise Information, Systems, Portugal, 2007, DOI: $10.5220 / 0002370602120220$

[4] S.Haseloff, "Context Awareness in Information Logistics", $\mathrm{PhD}$ dissertation, Technischen Universität Berlin, Germany, 2005.

[5] F. Markus, Information Logistics in Supply Chain Networks. Concept, Empirical Analysis, and Design. Ibidem Verlag, Hannover, Germany, 2004

[6] S. Grolik, Information Logistics - Decentralization Approaches of Information Allocation in Information Exchange Networks. Ibidem-Verlag, Germany, 2007

[7] B. Dinter, R. Winter, "Information Logistics Strategy Analysis of Current Practices and Proposal of a Framework" in Proceedings of the 42nd Hawaii International Conference on System Sciences, IEEE, Hawaii, 2009, DOI: 10.1109/HICSS.2009.253

[8] T. Bucher, and B. Dinter, "Process Orientation of Information Logistics - An Empirical Analysis to Assess Benefits, Design Factors, and Realization Approaches" in Proceeding of the 41st Hawaii International Conference on System Sciences, Hawaii, 2008 DOI: $10.1109 / \mathrm{HICSS} .2008 .361$

[9] W. Olthof, J. de Haan, J.Willems, Information Logistics, White Paper, NRG/Nashuatec Benelux, 2008

[10] Object Management Group (OMG), Unified Modeling Language v. 2.4.1, http://www.uml.org.

[11] Object Management Group (OMG), Business Process Model and Notation v.2.0, http://www.omg.org.

[12] L. Fuentes-Fernandez, A. Vallecillo-Moreno, "An introduction to UML profiles" in UPGRADE Vol. V, No. 2, April 2004.

[13] T.S. Kuhn, "The Structure of Scientific Revolutions", University of Chicago Press. Chicago, 1970.

[14] R. Floyd, "The paradigms of programming", in Communications of the ACM, 22 (8), 1979, DOI:10.1145/359138.359140 
[15] S.H. Kaisler, "Software paradigms" Wiley \& Sons. Inc. New Jersey, 2005.

[16] Giese H., Levendovszky T., Vanghekuve H., "Summary of the Workshop on Multi-Paradigm Modeling: Concepts and Tools" in T. Kuhne (Ed.): MoDELS 2006 Workshops, LNCS 4364, Springer-Verlag Berlin Heidelberg, 2007.

[17] C. Hardebolle, F. Boulanger, "Exploring Multi-Paradigm Modeling Techniques" in SIMULATION, Vol. 85, Issue 11/12, Nov./Dec. 2009
[18] Council of Supply Chain Management Professionals (CSCMP), Supply Chain Managament Terms and Glossary Updated 2013, http://cscmp.org (access: 10.04.2015)

[19] A. Bytheway, Investing in Information The Information Management Body of Knowledge, Springer International Publishing, Switzerland, 2014, DOI: 10.1007/978-3-319-11909-0 2

[20] European Commission, Erasmus+ Programme Guide, http://ec.europa.eu/, 2014 (access 18.06.2015) 